Open Access

\title{
The effect of operational innovation and QM practices on organizational performance in the healthcare sector
}

\author{
DonHee Lee
}

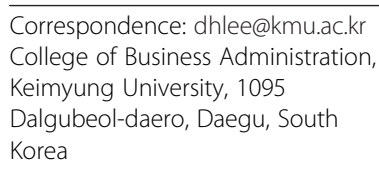

Correspondence: dhlee@kmu.ac.kr College of Business Administration, Keimyung University, 1095 Dalgubeol-daero, Daegu, South Korea

\begin{abstract}
This study examines the effects of operational innovation and quality management (QM) practices on organizational performance in healthcare organizations. More specifically, this study explores relationships of operational innovation and QM practices on organizational performance. The proposed research model was tested using structural equation modeling through a set of hypotheses, based on the data collected from 239 hospitals each with more than 100 beds. The results indicated positive effects of operational innovation on QM practices which eventually had a positive impact on organizational performance. The study also found positive relationships between process improvement and the medical IT system and QM practices. In addition, the results showed positive effects of quality improvement and safety practices on organizational performance.
\end{abstract}

Keywords: Operational innovation, QM practices, Organizational performance

\section{Background}

Today the healthcare industry is under a great deal of pressure to reduce healthcare costs [1-3]. Although most healthcare organizations attempt to reduce healthcare cost, many of their efforts are counterproductive $[3,4]$. For instance, if physicians try to save medical cost, they may need to spend less time on treatment processes that are poorly reimbursed under the care service mechanism. Thus, to reduce cost, healthcare providers need to first innovate their business processes to become more efficient. Such innovation efforts should focus on the effective application of medical information technology (IT) systems and quality management (QM) practices.

As healthcare organizations strive to improve the quality of care service, they should focus on patient safety and outcomes [5-7]. Hence healthcare has become a critical global issue service quality and patient safety have become the primary sources of competitive advantage. Thus, healthcare providers invest a great deal of financial and human resources to promoting innovations through purchasing medical devices and medical technology and systems to saving medical cost, and training staff to preventing medical errors and improving processes. Such innovations help achieve operational efficiency and quality management practices, which in turn are expected to improve organizational performance [8].

\section{Springer}

(c) 2015 Lee. Open Access This article is distributed under the terms of the Creative Commons Attribution 4.0 International License (http://creativecommons.org/licenses/by/4.0/), which permits unrestricted use, distribution, and reproduction in any medium, provided you give appropriate credit to the original author(s) and the source, provide a link to the Creative Commons license, and indicate if changes were made. 
Innovation, for hospitals, has been equated to economic survival because of pressures of the market, insurance companies, and government regulations for reducing healthcare costs. Some hospitals have reacted to the pressure by merging and consolidating [9], while others have attempted to be more innovative with new technologies (e.g., mHealth through mobile devices, telemedicine, telecare, U-care, and patient home monitoring).

As healthcare expenses grow, previous studies have focused mainly on reducing the delivery cost in the supply chain $[8,10]$ and the overall organizational performance $[10$, 11]. Specifically, studies have urged the leaders of hospitals to focus on cost containment through lower acquisition costs for materials while maintaining high quality [10].

However, there has been a paucity of research that examines the influence of operational innovation on organizational performance in healthcare. Based on a review of the literature on operational innovation in the healthcare sector, this study examines how operational innovation influences organizational performance, through enhanced process improvement, medical IT systems, and QM practices. More specifically, this study attempts to address the following research questions: (1) Does operational innovation impact QM practices? (2) Do process improvement and medical technology/system of operational innovation have an impact on QM practices such as quality improvement and safety procedures? (3) Do quality improvement and safety practices impact organizational performance?

The rest of the paper is organized as follows: Section 2 reviews relevant literature on the innovation imperative in the healthcare industry; Section 3 develops theoretical base for this study and the hypotheses to be tested; Section 4 describes the research methodology; Section 5 reports results; and Section 6 presents conclusion and discussion of the results and limitations of the study.

\section{Review of relevant literature}

\section{Characteristics of healthcare industry for innovation}

The hospital is a complex entity which unique characteristics as compared to other industries. The healthcare industry has many challenges for innovation including higher quality of care and services through promoting efficient operations and a creative work procedures. Especially, the chronic staff shortages, the rising need for specialized care and the maintenance of accurate patient databases, paired with challenges such as the threat of antibiotic-resistant bacteria, a rising number of uninsured patients and the increasing cost of medication need to be managed by healthcare providers as competently as possible.

For hospitals, their goals are to provide the best products and services to patients and employees, reduce carriage and maintenance cost, improve operational efficiency, and apply advanced technologies to internal (e.g., each department) and external (e.g., customers) functions. For patients, on the other hand, they want a high quality care through the best available products and services as well as competent medical staff. Furthermore, patients seek a variety of information when they search through the Internet, medical magazines, or other information systems.

\section{Operational innovation}

Organizational change is generally slow, painful, difficult and uncertain. The healthcare industry also is no exception in this regard [1]. However, without change or innovation, 
the healthcare delivery service will not improve in terms of its quality and cost. Thus, healthcare providers must constantly explore innovation and new ideas to create new value throughout their complex delivery systems. The innovation might include applications of new technologies, change in operational processes and/or convergence of the various ideas and systems.

Healthcare has a tremendous headroom for profitable innovation. A study by Länsisalmi et al. [12] reported that $62 \%$ of healthcare organizations agreed that they need continuous innovation. Hospitals need to search for new value creating opportunities in the global competitive environment (e.g., medical tourism). Kenagy [13] presented interesting cases of past innovation in healthcare: "The Mayo Clinic, starting with two frontier Minnesota surgeons, had the disruptive idea that there is 'no place for individualism in healthcare'; Baylor University Hospital's Depression-era innovation of guaranteeing Dallas schoolteachers 21 days of hospital care for $\$ 6$ per year became Blue Cross; and the inability to obtain healthcare by World War II shipyard workers and the technologically simple innovations of capitation and salaried physicians led to Kaiser Permanente, the largest healthcare organization in America." These examples of innovation in healthcare mean that innovations have played critical roles in successfully serving patients and potential customers and creating value in the healthcare system.

Operational innovation refers to tools that improve organizational processes that are needed for effective and seamless interactions among medical staffs, administrators and patients as customers [8]. Thus, operational innovation allows for reduction in cost and lead time, creation of efficient operational strategies, provision of consistent service quality, and patients safety $[1,3]$.

Hospitals that promote operational innovation seek new opportunities for customer value by process improvements and advanced medical IT systems. A hospital's ability to develop innovations that solve problems quickly and create new products or services for a faster and easier patient treatment is the engine for efficient processes and operations. Also, medical technologies/systems that connect the many silos of information in the healthcare system helps improve care quality and increase productivity, flexibility, and positive relationships with customers [14, 15].

An organizational environment that fosters continuous innovation contributes to successful process improvement $[16,17]$. An efficient operational process contributes to cost savings in healthcare organizations through the best practices or approaches. Process improvement impacts on the achievement of organizational goals through enhanced employee work performance [18]. Thus, managers need to recognize that effective operational innovation is more important than simply searching for cost reduction activities and exhorting medical staff for better patient care. This means that operational innovation efforts can drive improved service delivery processes. Already some hospitals use such innovation tools as lean management and six sigma concepts, value chain innovation for process improvement, and the Baldrige criteria for performance excellence $[3,14]$.

When healthcare organizations are implementing medical IT systems, they can expect multiple site access within departments, reduced medical errors and wasted time, increased secure storage and process efficiency, and rapid search capabilities $[7,15]$. The advanced medical IT systems can support medical staffs in their efforts to improve quality of care services through enhanced (efficiency, flexibility, cost saving, safety, and 
service quality $[8,19]$. For example, the use of an electronic health record (EHR) in a hospital, which contains patient healthcare service information, has increased rapidly from 18 \% in 2001 to 78 \% in 2013 [20]. Also EHR is suggested as a key tool in improving healthcare quality through reduced medical errors and improved patient safety [21].

There are many successful cases implementation of medical IT systems. For example, EHR helps simplify the complicated web of varying physician practices [22]. 'Robotic Check-Ups', one of new medical technologies, 'is a cost-effective and increasingly potent means to connect clinics in the vast and medically underserved rural regions of the United States with big city medical centers and their specialists' [23]. Medical IT systems can lead hospital work situations toward more effective business processes for collecting data of the patient to analyze medical treatment and/or diagnosis and improve the safety of an environment by reducing unnecessary complexities, designing systems for simpler controllability or monitoring [18]. In addition, removing duplicated information from the collected data positively affects operational efficiency through appropriate use of medical IT systems such as EHR, personal health records, and health information exchange (HIE) systems.

These examples imply that healthcare organizations strive to leverage medical technologies/systems to systematize and standardize medical information for better handling of the data, reduction of cost, and obtaining higher degrees of clarity and transparency among the units within a hospital and ultimately for better patient care. Thus, hospitals should acquire appropriate medical IT systems to provide accurate medical information of patients based on operational innovation. In addition, the use of medical IT systems have several potential benefits for operational innovation as follows: better communicate with colleagues and patients, improved operational processes, and providing timely information to improve patient care [24, 25].

Operational innovation in this study includes tools that improve operational activities through process improvement and medical IT systems. The goal of operational innovation is to increase the efficiency of processes and improve the flow of information among units in a hospital. In this study, operational innovation can be divided into process improvement and the medical information technology (IT) system. The proposed model in this study developed measurement items of operational innovation based on studies of Barki et al. [25], Lee et al. [8], and Staples et al. [24].

\section{Quality management practices}

Quality management (QM) is an organizational efforts to achieve quality of products and services, performance, and a bigger market share. The concept of quality in the healthcare system includes structures, processes, and outcomes, which reflect customer satisfaction and continuous improvement of administrative processes [6, 11]. Common QM practices of a hospital show the result of a treatment or a healthcare service unit [7, 11]. QM practices to improve quality of care service usually include quality programs, awards, and tools. According to Lee et al. [8], QM practices have a positive relationship with organizational performance in the healthcare industry. Thus, QM practices are a key factor in the value-added process of care services.

As the goal of medical safety is to provide a comfortable and safe environment to patients, potential consumers, and employees in the healthcare system, safety is important 
at the first and later stages for both patients and the work place. When patients visit a hospital, if they have uncomfortable feelings about the environment, they will be concerned as to whether they would receive best care services with advanced medical equipment and medicine by competent medical staff. Thus, healthcare organizations should provide care services with modern facilities in a safe environment. In addition healthcare units can create and promote a culture of patient safety, which in turn enhance patient satisfaction in the competitive environment. For example, as medical tourism is one of the fastest growing areas of health-care, most customers seek safer and more comfortable medical environments with high quality of care service at a reasonable cost, a variety of medical procedures, excellent facilities, and unique destinations [26].

The Malcolm Baldrige Healthcare Criteria for Performance (MBHCP) excellence model, introduced in 1995, includes seven categories (leadership; strategic planning; customer focus; measurement, analysis, and knowledge management; workforce focus; process management; and results). The leadership criterion especially emphasizes continuous improvement towards creating and promoting a culture of patient safety environment [2]. The Quality Healthcare Accreditation (QHA), a certification institution of England, considers safety of patients, employees and people as a top priority. Other certification institution for healthcare quality, such as JCI (Joint Commission International) and ACI (Accreditation Canada International), also include patient's safety as an important criterion of service quality.

In this study, QM practices can be divided into improvement of quality of care and safety. The one criterion, process management, of the MBHCP criteria emphasizes continuous process improvement as "how the organization designs its work system, how it designs, manages, and improves its key processes for implementing those work systems to deliver value to patients and stakeholders and achieve organizational success and sustainability, and how the organization is ready for emergencies [27]." It means that hospitals can improve their processes by enhancing quality of care and safety. Thus, this study modified the measurement items of QM practices suggested by Dey et al. [28], Lee et al. [2], and the criteria of MBHCP [27].

\section{Organizational performance}

Healthcare providers consider several aspects to improve organizational performance as the result of organizational goals achieved through effective management strategies and techniques. Organizational performance can be measured by various approaches because hospitals attempt to strategically manage for cost savings, improved quality of care, and better support for front line workers to create patient value. Thus, organizational performance is important not only for all internal functions, as virtually every activity is linked in the hospital, but also for patients and suppliers.

Healthcare activities include all activities involved with purchasing, movement of products as well as returning or exchanging damaged products. If a physician makes a mistake during the diagnosis or treatment process of a patient using damaged products, this medical error negatively impacts the perception of the patient as dissatisfaction, which in turn negatively affects organizational performance. It means that satisfied patients positively influence organizational performance through improved customer loyalty, word-of-mouth recommendations, and eventually profitability. 
A previous study suggested that companies generally measure financial and nonfinancial performance outcomes that are related to certain aspects of strategy and operations [8], while some firms and researchers have focused on financial performance, while others concentrated on operational performance [29]. In the study, organizational performance is measured by outcomes of quality improvement and safety practices as part of QM practices.

The MBHCP excellence model measures performance by outcomes achieved in six categories. The category of results examines 'the organization's performance and improvement in all key areas and performance levels of competitors and other organizations with similar health-care service offerings' [27]. A study of Lee et al. [8] measured organizational performance by quality, competitive position, and the service level of the healthcare provider. Thus, this study modified the measurement items of organizational performance, based on studies of Lee et al. [2] and the criteria of the MBHCP excellence model. Therefore, this study attempts to measure organizational performance in both quality and operational improvement based on relevant literature.

\section{Research model and hypotheses}

The proposed research model (Fig. 1) examines the effects of operational innovation and QM practices on organizational performance in the healthcare industry. Provided that an important goal of a hospital is to maximize the overall value of products and service, and to reduce cost, it is important to analyze the effects of how operational innovation will improve organizational performance through QM practices.

Process improvement and medical IT systems for operational innovation lead to value creation for customers, increased efficiency and accuracy of care service delivery, and quality care [30]. As a result, a growing number of hospitals are seeking innovation to bring efficiencies in their operation to remain competitive [1].

As process improvement and medical IT systems of operational innovation support consistent quality of care services, it can influence QM practices to reduce process variance for preventing rework and errors, decrease errors or defects, provide high quality of care service and provide safe practices [2, 15, 31]. A more comfortable environment for patients is ensured as the organization develops insight based on experiences about why problems occurred, which solutions worked, and how to implement solutions [31].

Also, medical IT systems are $\mathrm{n}$ imperative for providing ready access to patient records, accurate information about patients, and supply requirements for improving QM practices. QM practices can be achieved through process improvement and medical IT systems because QM practices adopt a number of management principles to
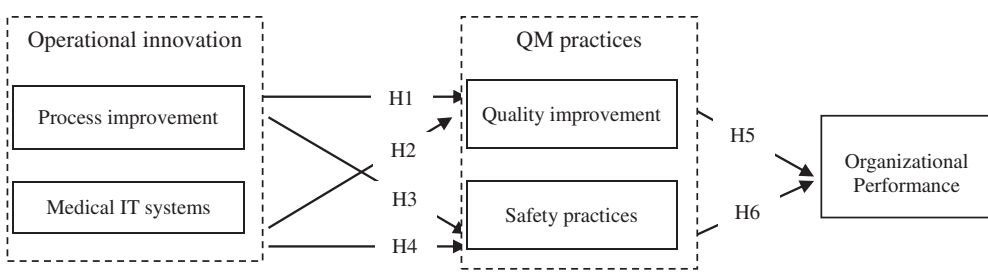

Fig. 1 Proposed research model 
improve customer satisfaction and performance. Thus, operational innovation would have a positive relationship with QM practices. The following hypotheses are proposed:

H1: Process improvement will positively affect quality improvement.

H2: Medical IT system implementation will positively affect quality improvement.

H3: Process improvement will positively affect safety practices.

H4: Medical IT system implementation will positively affect safety practices.

As discussed earlier, the key role of QM practices to improve organizational performance [2, 31, 32]. Lee et al. [2] suggested that organizational performance could be enhanced through improved quality of care service. Creating a culture of quality and safety for patients is essential to successfully improve organizational performance in the hospital.

QM practices ensure that processes are followed and customers are satisfied. This means that QM practices positively impacts organizational performance. Organizational performance can be achieved through QM practices, and then organizations can improve their business performance. Consequently, quality improvement and safety practices of QM practices may have a positive relationship with organizational performance. The following hypotheses are suggested:

H5: Quality improvement will positively affect organizational performance.

H6: Safety practices will positively affect organizational performance.

\section{Methods}

Due to the nature of the data needed to perform an empirical study, hospitals with more than 100 beds in South Korea were identified as most appropriate population sampling. The reason for this sampling approach used in this study was as follows: according to the Medical Herald [33], market value of healthcare in Korea was 9.2 billion dollars in 2009 and would increase at the annual average growth rate of $6.8 \%$ to 2016 while hospitals try to reduce operational cost and improve service quality. Medium to large Korean hospitals offer high-tech medical services by combining advanced IT and biotech, and continue to make significant advances in the field.

\section{Data collection}

A survey questionnaire was developed to test the proposed model, using the double translation protocol [34]. The questionnaire was developed in English first and then translated into Korean by the researcher who is an operations management faculty in South Korea. The Korean version was translated back into English by into American operations management experts who are bilingual. The two English version questionnaires based on the double translation protocol had no significant difference.

Due to the characteristics of a hospital, it was difficult to meet care team members during working hours for data collection. Firstly, we contacted the manager of each department for data collection, and then questionnaires were randomly distributed to care team members by the hospital's manager by e-mail using the Google Survey Tool. A total of questionnaires were distributed to care team members (e.g. doctors, nurses, pharmacist, 
administrator, and technicians) who have frequent contacts with patients. Subsequently, 239 hospitals returned useable questionnaires (a response rate of $47.8 \%$ ).

As shown in Table 1, the characteristics of hospitals and demographic information of respondents are followings: The types of surveyed hospitals included teaching (23.8 \%), foundation (37.7 \%), public (12.6\%), and private hospitals (25.9\%). The categorized hospital type included second (71.1 \%) and third tier (28.9\%). Occupations of the employee respondents were as follows: nurse, $35.7 \%$; administrator, $28.5 \%$; medical technician, $23.4 \%$; physician, $10.2 \%$; and pharmacist, $2.2 \%$.

\section{Variables}

Variable items utilized a five-point Likert scale to measure the constructs. The variables used in this study to measure model constructs were mostly based on previous studies, although some measures were modified to adapt to this research (Table 2).

\section{Reliability and validity analysis}

Reliability was tested based on Cronbach's alpha values (Table 3). All of the coefficients for the constructs exceeded the threshold value of .70 for exploratory constructs [35]. All of the study constructs for the five latent variables had Cronbach's alpha larger than .7, which revealed high reliability at the .05 level.

For validity test, principal component analysis (PCA) based on Varimax rotation was utilized. Also, confirmatory factor analysis (CFA) was employed to test how well measured variables represent the constructs. Statistics of the PCA and CFA are shown in Table 3.

Fornell and Larcher [36] recommended the average variance extracted by each construct should be greater than 0.5 . All measurement items met the threshold value. The

Table 1 Hospital and respondents' characteristics

\begin{tabular}{|c|c|c|c|}
\hline Hospitals' characteristics & & Frequency & $\overline{\text { Percent }(\%)}$ \\
\hline \multirow[t]{4}{*}{ Hospital type } & Teaching & 57 & 23.82 \\
\hline & Foundation & 90 & 37.71 \\
\hline & Public & 30 & 12.62 \\
\hline & Private & 62 & 25.85 \\
\hline \multirow[t]{2}{*}{ Categorized hospital type } & Third tier & 90 & 37.54 \\
\hline & Second tier & 149 & 62.46 \\
\hline \multirow[t]{4}{*}{ Number of beds } & More than 1000 & 7 & 2.78 \\
\hline & More than 500 & 91 & 38.26 \\
\hline & More than 200 to 500 & 87 & 36.24 \\
\hline & 100 to 200 & 54 & 22.72 \\
\hline Respondents' characteristics & & Frequency & Percent (\%) \\
\hline \multirow[t]{5}{*}{ Position } & Nurse & 85 & 35.71 \\
\hline & Administrator & 68 & 28.39 \\
\hline & Medical technician & 56 & 23.42 \\
\hline & Physician & 25 & 10.28 \\
\hline & Pharmacist & 5 & 2.20 \\
\hline Total respondents $=239$ & & & \\
\hline
\end{tabular}


Table 2 Items of measurements

\begin{tabular}{|c|c|c|c|}
\hline Component & & $\begin{array}{l}\text { Variable (Likert type 5-point Scale, } \\
1=\text { Very bad; } 5 \text { = Very good) }\end{array}$ & References \\
\hline \multirow[t]{7}{*}{$\begin{array}{l}\text { Operational } \\
\text { innovation }\end{array}$} & \multirow[t]{4}{*}{$\begin{array}{l}\text { Process } \\
\text { improvement }\end{array}$} & $\begin{array}{l}\text { continuous innovation in core } \\
\text { processes (PI1) }\end{array}$ & \multirow[t]{7}{*}{$\begin{array}{l}\text { Barki et al. (2007) [25], Lee et al. } \\
\text { (2011) [8], Staples et al. (2002) [24] }\end{array}$} \\
\hline & & innovation to reduce cost (PI2) & \\
\hline & & effectiveness of processes (PI3) & \\
\hline & & innovative solutions (P|4) & \\
\hline & \multirow{3}{*}{$\begin{array}{l}\text { Medical IT } \\
\text { systems }\end{array}$} & convenient to access information (IT1) & \\
\hline & & new technological innovation (IT2) & \\
\hline & & well-informed guide material (IT3) & \\
\hline \multirow{7}{*}{$\begin{array}{l}\text { Quality } \\
\text { management (QM) } \\
\text { practices }\end{array}$} & \multirow[t]{3}{*}{$\begin{array}{l}\text { Quality } \\
\text { improvement }\end{array}$} & $\begin{array}{l}\text { emphasis of quality management } \\
\text { (QM1) }\end{array}$ & \multirow[t]{7}{*}{$\begin{array}{l}\text { Dey et al. (2007) [28], Lee et al. } \\
\text { (2013) [2], NIST (2010) [27]. }\end{array}$} \\
\hline & & consistency of order fulfillment (QM2), & \\
\hline & & $\begin{array}{l}\text { resolution of problems and } \\
\text { complaints (QM3) }\end{array}$ & \\
\hline & \multirow{4}{*}{$\begin{array}{l}\text { Safety } \\
\text { practices }\end{array}$} & safety as a top priority (SP1) & \\
\hline & & a clean environment (SP2) & \\
\hline & & $\begin{array}{l}\text { hospital structure designed to avoid } \\
\text { disturbing the patient moves (SP3) }\end{array}$ & \\
\hline & & $\begin{array}{l}\text { alleviating probable risk mechanisms } \\
\text { (SP4) }\end{array}$ & \\
\hline \multirow{4}{*}{\multicolumn{2}{|c|}{ Organizational performance }} & overall, good performance (OP1) & \multirow{4}{*}{$\begin{array}{l}\text { Lee et al. (2013) [2], NIST (2010) } \\
\text { [27] }\end{array}$} \\
\hline & & high quality of care service (OP2) & \\
\hline & & higher morale (OP3), & \\
\hline & & liking the hospital (OP4) & \\
\hline
\end{tabular}

loading values for all the factors, shown in Table 3, ranged from .742 to .916. Eigen values and percent of variance explained for each construct are also shown in Table 3.

The standardized factor loadings and $\mathrm{t}$-values for measurement variables, and results of CFAs to test measurement models for each construct separately using the AMOS program, are presented in Table 3. The values of standardized regression weight of process improvement, medical IT systems, quality improvement, safety practices, and organizational performance were all greater than .5 and all variables proposed by the study were statistically significant at the .05 level.

The results of goodness of fit test for the measurement model summarized in Table 4, show the values of chi-square $(\chi 2)$, degrees of freedom, GFI, AGFI, CFI, RMSEA, RMR, and p-value of each model. Compared to the recommended values for the goodness of fit tests, the values of GFI, AGFI, CFI, RMR, $\chi 2$, and the p-value were satisfactory, while the value of AGFI (.863) was not.

The square roots of average variance extracted (AVE) of latent variables are shown in Table 5, while the off-diagonal elements are the correlation between latent variables. For adequate discriminant validity, the square root of the AVE of any latent variable should be greater than the correlation between this particular latent variable and other latent variables [37].

As the values of composite reliability (CR) of process improvement, medical IT systems, quality improvement, safety practices, and organizational performance were all greater than .7, convergent validity met the threshold. Statistics shown in Table 5 therefore 
Table 3 Results of PCA and CFA

\begin{tabular}{|c|c|c|c|c|c|c|c|c|}
\hline \multirow[b]{2}{*}{ Constructs } & & \multirow[b]{2}{*}{ Variables } & \multicolumn{3}{|l|}{ PCA } & \multicolumn{2}{|l|}{ CFA } & \multirow[b]{2}{*}{$\begin{array}{l}\text { Cronbach's } \\
\text { Alphas }\end{array}$} \\
\hline & & & $\begin{array}{l}\text { Eigen } \\
\text { value }\end{array}$ & $\begin{array}{l}\text { Percent of } \\
\text { variance } \\
\text { explained }\end{array}$ & $\begin{array}{l}\text { Factor } \\
\text { loadings }\end{array}$ & $\begin{array}{l}\text { Standardized } \\
\text { loading }\end{array}$ & $t$-value & \\
\hline \multirow{7}{*}{$\begin{array}{l}\text { Operational } \\
\text { Innovation }\end{array}$} & \multirow{5}{*}{$\begin{array}{l}\text { Process } \\
\text { Improvement (PI) }\end{array}$} & PI1 & \multirow{5}{*}{2.988} & \multirow{4}{*}{16.598} & .889 & .834 & 13.975 & \multirow{5}{*}{.896} \\
\hline & & $\mathrm{Pl} 2$ & & & .879 & .861 & 14.465 & \\
\hline & & $\mathrm{Pl} 3$ & & & .916 & .838 & 14.020 & \\
\hline & & $\mathrm{PI} 4$ & & & .801 & .791 & - & \\
\hline & & IT1 & & \multirow{3}{*}{9.280} & .774 & .639 & 6.279 & \\
\hline & \multirow[t]{2}{*}{ Medical IT Systems } & $\mathrm{IT} 2$ & \multirow[t]{2}{*}{1.670} & & .794 & .666 & 6.325 & \multirow[t]{2}{*}{.734} \\
\hline & & IT3 & & & .742 & .611 & - & \\
\hline \multirow{7}{*}{$\begin{array}{l}\text { QM } \\
\text { Practices }\end{array}$} & \multirow{3}{*}{$\begin{array}{l}\text { Quality } \\
\text { Improvement (QI) }\end{array}$} & QM1 & \multirow{3}{*}{1.824} & \multirow{3}{*}{10.133} & .753 & .546 & 8.038 & \multirow{3}{*}{.809} \\
\hline & & QM2 & & & .798 & .662 & 9.827 & \\
\hline & & QM3 & & & .800 & .748 & - & \\
\hline & \multirow{4}{*}{ Safety practices (SP) } & SP1 & \multirow{4}{*}{3.219} & \multirow{4}{*}{17.885} & .864 & .794 & 10.334 & \multirow{4}{*}{.904} \\
\hline & & SP2 & & & .894 & .782 & 10.216 & \\
\hline & & SP3 & & & .755 & .667 & 8.969 & \\
\hline & & SP4 & & & .754 & .667 & - & \\
\hline \multirow{4}{*}{\multicolumn{2}{|c|}{ Organizational Performance }} & OP1 & \multirow{4}{*}{3.827} & \multirow{4}{*}{21.262} & .785 & .714 & 11.128 & \multirow{4}{*}{.904} \\
\hline & & OP2 & & & .878 & .831 & 13.055 & \\
\hline & & OP3 & & & .812 & .761 & 11.958 & \\
\hline & & OP4 & & & .835 & .798 & - & \\
\hline
\end{tabular}

satisfied this requirement, lending evidence to discriminant validity. Also, the results of the correlation between each variable are shown in Table 5 .

\section{Results}

AMOS analytical results for the study model and estimates for the model fit measures are analyzed. As a result of the goodness of fit test, compared to the recommended values for the goodness of fit tests, in this model the value of GFI (.916), CFI (.958), RMSEA (.052), RMR (.032) were good fit, and chi-square (207.771), df (126) and p-value (.000) were significant. However, the value of AFGI (.886) did not meet on the recommended values.

The results of significance tests for paths of the model are shown in Table 6. For H1 test, the standardized path coefficient between process improvement and quality improvement was significant $(\beta=.292, p<.001)$. Thus, $\mathrm{H} 1$ is supported. To drive process improvement as part of operational innovation, leaders should develop effective processes and provide support with right resources to improve quality of care $[1,3,14]$. When operational innovation is focused on improving operational processes, innovation leads to providing better value to customers through the reduced cost and improved quality of products and services [1]. This study had a similar result as previous studies.

Table 4 Results of fit indices for CFA

\begin{tabular}{lllllllll}
\hline Model & $\mathrm{X}^{2}$ & d.f & $p$-value & GFI & AGFI & CFI & RMSEA & RMR \\
\hline Model & 266.834 & 125 & .000 & .901 & .863 & .927 & .069 & .040 \\
Recommended value & & & & $\geq .9$ & $\geq .9$ & $\geq .9$ & $\leq .08$ & $\leq .08$
\end{tabular}


Table 5 Correlation matrix and average variance extracted (AVE)

\begin{tabular}{|c|c|c|c|c|c|}
\hline Factor & $\begin{array}{l}\text { Process } \\
\text { improvement }\end{array}$ & $\begin{array}{l}\text { Medical IT } \\
\text { systems }\end{array}$ & $\begin{array}{l}\text { Quality } \\
\text { improvement }\end{array}$ & $\begin{array}{l}\text { Safety } \\
\text { practices }\end{array}$ & $\begin{array}{l}\text { Organizational } \\
\text { performance }\end{array}$ \\
\hline $\begin{array}{l}\text { Process } \\
\text { improvement }\end{array}$ & 1 & & & & \\
\hline Medical IT systems & $.405^{*}$ & 1 & & & \\
\hline Quality improvement & $.387^{*}$ & $.264^{*}$ & 1 & & \\
\hline Safety practices & $.227^{*}$ & $.287^{*}$ & $.233^{*}$ & 1 & \\
\hline $\begin{array}{l}\text { Organizational } \\
\text { performance }\end{array}$ & $.410^{*}$ & $.469^{*}$ & $.649^{*}$ & $.469^{*}$ & 1 \\
\hline$C R$ & .932 & .783 & .756 & .860 & .897 \\
\hline Sqrt (AVE) & .879 & .739 & .715 & .779 & .828 \\
\hline
\end{tabular}

For $\mathrm{H} 2$ test, the standardized path coefficient between medical IT systems as part of operational innovation and quality improvement was significant $(\beta=.218, p<.05)$. Therefore, $\mathrm{H} 2$ is supported. The benefits and problems of IT usage were reported in previous studies as follows: for benefits; reduction of redundant tests, improved quality of healthcare providers, and improved patient outcomes [38, 39]; and for problems; lack of information on how to use IT, complication in the decision making process, and personnel issues. This study had similar results as previous studies. Thus, leaders should know about how and where to direct their operations investments to improve quality of care service, maximize business results, and to apply better IT through the operational innovation.

H3 tests the effect of process improvement as part of operational innovation on safety practices. A standardized path coefficient between process improvement and safety practices was significant $(\beta=.305, p<.001)$. Thus, H3 is supported. Process improvement could directly influence patient safety practices [40]. The Institute of Medicine (IOM) suggested that today's healthcare industry functions should include a safe environment for patient in care processes to achieve the desired aims and avoid predisposed harm [41]. Also, the National Quality Forum and the Joint Commission suggested quality and patient safety to improve healthcare in care delivery processes. Thus, process improvement can drive safety practices as an organizational priority.

For $\mathrm{H} 4$ test, the standardized path coefficient between medical IT systems as part of operational innovation and safety practices was not significant $(\beta=.136, p>05)$.

Table 6 Results of significance test for paths of the model

\begin{tabular}{|c|c|c|c|c|c|}
\hline Path & $\begin{array}{l}\text { Path } \\
\text { coefficient }\end{array}$ & S.E. & t-value & $p$-value & Hypothesis test \\
\hline Process Improvement $\rightarrow$ Quality improvement & .292 & .076 & 3.266 & $.001^{* *}$ & Supported H1 \\
\hline Medical IT systems $\rightarrow$ Quality improvement & .281 & .121 & 2.742 & $.006^{*}$ & Supported H2 \\
\hline Process improvement $\rightarrow$ Safety practices & .305 & .072 & 3.862 & $.000^{* *}$ & Supported H3 \\
\hline Medical IT systems $\rightarrow$ Safety practices & .136 & .110 & 1.579 & .114 & $\begin{array}{l}\text { Not supported } \\
\text { H4 }\end{array}$ \\
\hline $\begin{array}{l}\text { Quality improvement } \rightarrow \text { Organizational } \\
\text { performance }\end{array}$ & .798 & .173 & 5.289 & $.000^{* *}$ & Supported H5 \\
\hline Safety practices $\rightarrow$ Organizational performance & .330 & .142 & 2.473 & $.013^{*}$ & Supported H6 \\
\hline
\end{tabular}


Therefore, H4 was not supported. Using medical IT systems appears a typical safety practice in hospital rather than a strategic investment decision in technology as a consequence of the safety culture. However many researchers reported medical effects of IT systems implementation on reducing errors associated with dosing, decreasing human errors through automation, and improving medication safety [42]. This study has similar results as previous studies.

For $\mathrm{H} 5$ test, the standardized path coefficient between quality improvement as part of QM practices and organizational performance was significant $(\beta=.798, p<.001)$. For H6 test, the standardized path coefficient between safety practices as part of QM practices and organizational performance was significant $(\beta=.330, p<.05)$. Then, both H5 and $\mathrm{H} 6$ were supported. As discuss in many previous studies, there is a strong relationship between QM practices and organizational performance. This study had a similar result as previous studies.

\section{Discussion and conclusions}

Today, the healthcare service industry has a priority on reducing cost, and improving operational efficiency, quality of care service, safety, and customer satisfaction. Healthcare leaders and managers strive to invest in advanced systems and/or technologies with the expectations for improved quality of care and reduced medical error and cost containment. Healthcare service, however, is a complex system and has many challenges.

This study proposed a research model to investigate how operational innovation influences QM practice and organizational performance for health-care organizations. The six hypotheses proposed and tested using data collected in South Korea.

The results of the study shed new insights about how hospitals can implement operational innovation to improve their operations, QM practice and eventually organizational performance. The findings of the study revealed that process improvement and medical IT systems as part of operational innovation are associated with improved quality improvement (.291) and improved safety practices (.281). This result seems reasonable in that all of the efforts to improve quality improvement and safety practices are related to engagements and attitudes of medical staff through operational innovation. The study indicated that quality improvement (.798) and safety practices (.330) as part of QM practices are associated with organizational performance. Since employees are the direct contact point with customers, they directly affect quality of care service. Thus, these results indicate that the effectiveness of QM practices are important to patient satisfaction [32, 43]. This seems to be reasonable given that all of the efforts to improve quality of care service and safety are important for organizational performance. Thus, it is critical for healthcare organizations to develop and undertake operational innovations in their existing work systems and processes to improve employees' task efficiency for QM practices and organizational performance.

The study did not show a statistically significant relationship between medical IT systems and safety practices (H4). The reason for this result could be that some hospitals do not have sufficient system strength to develop strategic planning for safety practices.

There are some limitations of this study. First the survey data used in this study was collected from hospitals with more than 100 beds in South Korea. Second, this study did not consider the level of medical IT systems investment. Since there are many small-sized hospitals, a comparative study of the small versus large hospitals in terms of operational 
innovation might yield interesting results. Third, in this study, organizational performance was measured by employee perception about quality and operational improvement of the hospital rather than objective measures. Thus, the generalizability of this study's results might be limited.

Future research should consider our limitations mentioned above using different size and type of hospitals. In addition, the future study should consider both longitudinal analysis as well as different healthcare environments, such as economic conditions and structural issue vis-a-vis nationized vs. privatized systems.

\section{Competing interests}

The authors declare that he/she has no competing interests.

Received: 10 September 2015 Accepted: 27 October 2015

Published online: 31 October 2015

\section{References}

1. Block D (2013) Disruptive innovation: contributing to a value-based health care system. The Free Library, Physician Exec 46-50

2. Lee S, Lee D, Olson D (2013) Health care quality management using MBHCP excellence model. Total Qual Manag Bus Excell 24(2):119-137

3. McDonald P, Mecklenburg R, Martin L (2015) The employer-led health care revolution. Harv Bus Rev 93(7):33-50

4. Kaplan R, Haas D (2014) How not to cut health care costs. Harv Bus Rev 92(11):116-122

5. Chong P, Calingo L, Reynolds G, Fisher D (2003) Using an innovative approach to shorten coaching and assessment time when applying the Baldrige health care criteria for performance excellence in a substance abuse treatment setting. Total Qual Manag Bus Excell 14(10):947-955

6. Raposo M, Alves H, Duarte P (2009) Dimensions of service quality and satisfaction in healthcare: a patient's satisfaction index. Serv Bus 3(1):85-100

7. Lee D (2012) Implementation of quality programs in health care organizations. Serv Bus 6(3):387-404

8. Lee D, Lee S, Schniederjans M (2011) Supply chain innovation and organizational performance in the health care industry. Int J Oper Prod Man 31(11):1193-1214

9. Reardon J, Reardon L (1995) The restructuring of the hospital services industry. J Econ Issues 29(4):1063-1083

10. Kumar A, Ozdamar L, Zhang N (2008) Supply chain redesign in the healthcare industry of Singapore. Supply Chain Manag 13(2):95-103

11. Minkman M, Ahaus K, Huijsman R (2007) Performance improvement based on integrated quality management models: what evidence do we have? a systematic literature review. Int J Qual Health Care 19(2):90-104

12. Länsisalmi H, Kivimäki M, Aalto P, Ruoranen R (2006) Innovation in healthcare: a systematic review of recent research. Nurs Sci Q 19(1):66-72

13. Kenagy J (2001) A brief commentary on disruptive innovation in health care: U.S. Senate committee on commerce. Science and Transportation, In Block D (2013) Disruptive innovation: contributing to a value-based health care system. The Free Library, Physician Executive 46-50.

14. Herzlinger R (2005) Innovating in health care framework. Harvard Business School Cases, Boston, pp 1-54

15. Lin C (2008) Determinants of the adoption of technological innovations by logistics service providers in China. Int J Technol Manag Sustain Dev 7(1):19-38

16. Adler P, Riley P, Kwon S, Signer J, Lee B, Satrasala R (2003) Performance improvement capability: keys to accelerating performance improvement in hospitals. Calif Manag Rev 45(2):12-33

17. McFadden K, Stock G, Gowen C III (2006) Implementation of patient safety initiatives in US hospitals. Int J Oper Prod Man 26(3):326-347

18. McFadden K, Henagan S, Gowen C III (2009) The patient safety chain: transformational leadership's effect on patient safety culture, initiatives, and outcomes. J Oper Manag 27(5):390-404

19. Davidson EJ, Chismar WG (2007) The interaction of institutionally triggered and technology-triggered social structure change: an investigation of computerized physician order entry. MIS Q 31(4):739-758

20. Hsiao C, Hing E (2014) Use and characteristics of electronic health record systems among office-based physician practices: United States, 2001-2013. NCHS Data Brief 143:1-8

21. DeSalvo KB (2014) Survey Says: EHR incentive program is on track. Health IT Buzz. http://www.healthit.gov/buzz-blog/ from-the-onc-desk/survey-ehr-incentive-program. Accessed 22 Oct 2015

22. Lorenzi N, Kouroubali A, Detmer D, Bloomrosen M (2009) How to successfully select and ilmplement electronic health records (EHR) in small ambulatory practice settings. BMC Med Inform Decis Mak 9:15-27

23. MacRae M (2013) Top 5 Medical Technology Innovations. ASME.org https://www.asme.org/engineering-topics/ articles/bioengineering/top-5-medical-technology-innovations. Accessed 22 Oct 2015

24. Staples S, Wong I, Seddon P (2002) Having expectations of information systems benefits that match received benefits: does it really matter? Inf Manag 40:115-131

25. Barki H, Titah R, Boffo C (2007) Information system use-related activity: an expanded behavioral conceptualization of individual-level information system use. Inf Syst Res 18(2):173-192

26. Ellin A (2009) Health care goes global. Delta sky magazine, Minneapolis, pp 112-118

27. National Institute of Standards and Technology (NIST) (2010). http://www.nist.gov/. Accessed 22 Oct 2015

28. Dey P, Hariharan S, Ho W (2007) Managing healthcare technology in quality management framework. Int J Technol Manag 40(1-3):45-68 
29. Kaplan R, Norton P (1992) The balanced score card - measures that drives performance. Harv Bus Rev 70(1):71-79

30. André B, Ringdal G, Loge J, Rannestad T, Laerum H, Kaasa S (2008) Experiences with the implementation of computerized tools in health care units: a review article. Int J Hum Comput Interact 24(8):753-775

31. Lapre M, Van Wassenhove L (2001) Creating and transferring knowledge for productivity improvement in factories. Manag Sci 47(10):1311-1325

32. Lee S, Lee D, Kang C (2012) The impact of high performance work systems in the health care industry: employee reactions, service quality, customer satisfaction, and customer loyalty. Serv Ind J 32(1):17-36

33. Medical Herald (2010) Introduction of Korean hospital IT. http://www.mediherald.com/news/ articleView.html?idxno=12770. Accessed 22 Oct 2015

34. Harkness J (2011) Guidelines for best practice in cross-cultural surveys, 3rd edn. Survey Research Center, Institute for Social Research, University of Michigan, Arbor

35. Nunnally J (1978) Psychometric theory, 2nd edn. McGraw-Hill, New York

36. Fornell C, Larcker D (1981) Evaluating structural equation models with unobservable variables and measurement error. J Mark Res 18(1):39-50

37. Barclay D, Higgins C, Thompson R (1995) The Partial Least Squares (PLS) approach to causal modeling: personal computer adoption and use an illustration. Technol Stud 2(2):285-309

38. Burt C, Sisk J (2005) Which physicians and practices are using electronic medical records? Health Affair 24(5):1334-1343

39. Garg A, Adhikari N, McDonald H, Rosas-Arellano M, Devereaux P, Beyene J, Sam J, Haynes R (2005) Effects of computerized clinical decision support systems on practitioner performance and patient outcomes. J Am Med Assoc 293(10):1223-1238

40. Lees M, Chapman P, Dickson S (2011) A process improvement strategy for patient safety. Healthcare Manage Forum 24(1):S25-S28

41. Institute of Medicine (IOM) (2001) Crossing the quality chasm: a new health system for the 21st century. National Academy Press, Washington

42. Johnstone P, Hendrickson J, Dernbach A (2003) Ancillary services in the health care industry: is Six Sigma reasonable? Qual Manag Health Care 12(1):53-63

43. Meyer S, Collier D (2001) An empirical test of the causal relationships in the Baldrige health care pilot criteria. J Oper Manag 19(4):403-425

Submit your manuscript to a SpringerOpen ${ }^{\circ}$ journal and benefit from:

- Convenient online submission

- Rigorous peer review

- Immediate publication on acceptance

- Open access: articles freely available online

- High visibility within the field

- Retaining the copyright to your article

Submit your next manuscript at $>$ springeropen.com 